\title{
Mineral processing in the Indian nuclear energy programme
}

\author{
T K S MURTHY \\ Uranium Extraction Division. Bhabha Atomic Research Centre, Trombay, Bombay \\ 400085 , India
}

\begin{abstract}
Uranium is the basic raw material for a nuclear energy programme. Uranium ore is processed in India by the well-known method of sulphuric acid, ion-exchange concentration and its final precipitation as magnesium diuranate-'yellow cake'. We have established a process for uranium recovery from the tailings of copper concentrators which also enables recovery of small amounts of copper, nickel and molybdenum present in the uranium ore. Another major activity of this centre has been the exploitation of mineral-rich beach sands to produce ilmenite, rutile, zircon and monazite. Downstream industries have also been established for chemical processing of these minerals. Production of niobium from low-grade ores and beryllium from beryl ore is also being carried out on a moderate scale.
\end{abstract}

Keywords. Mineral processing; nuclear energy programme; uranium extraction; niobium production.

\section{Introduction}

Mineral processing, in a wider sense, includes both physical and chemical processing of ores to obtain usable products. However, this paper highlights only some of the areas in mineral processing where work has been carried out as part of our nuclear energy programme. Some of the industrial activities in this field, under the Department of Atomic Energy (DAE), are also indicated. The Bhabha Atomic Research Centre (BARC) started investigations on the processing of ores of interest to the country's nuclear programme more than three decades ago. A number of processes dealing with both physical beneficiation and chemical processing of ores have been put into industrial practice. It is worth recalling that, unlike most of the industrially advanced countries, the Department of Atomic Energy in India looks after several aspects of processing of selected minerals-from mining through chemical processing and finally production of components required for nuclear energy generation. Thus, the scope of the activity is sufficiently large.

The primary materials of interest in nuclear field are the fissionable uranium, the fertile material thorium and materials like zirconium and niobium, used as alloys for nuclear fuel cladding and for components of reactor internals. These materials are obtained by processing of specific minerals and further chemical and metallurgical processing of the products. All these materials are produced in India under various establishments of DAE using processes largely developed within the organization and later scaled up to the required level.

\section{Uranium}

Uranium ore is mined and processed essentially by a hydrometallurgical route to obtain the 'yellow cake'. The well known method of sulphuric acid leach, ionexchange concentration and final precipitation of uranium as magnesium diuranate (MDU) has been followed. A simplified flow sheet is shown in figure 1. As in the case 


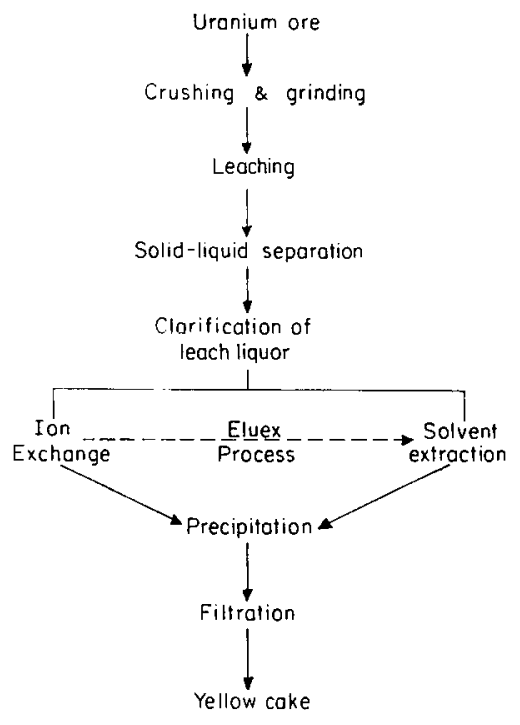

Figure 1. A simplified flow diagram showing major steps in conventional uranium ore processing.

of practically all uranium ores in the world attempts to beneficiate the low-grade ores $\left(0.4-1.0 \mathrm{~kg} \mathrm{U}_{3} \mathrm{O}_{8}\right.$ per ton) have been unsuccessful. However, some of the investigations by the Ore Dressing Laboratories of BARC on the recovery of uranium as a byproduct from the tailings of copper concentration plants and on the recovery of copper, nickel and molybdenum as byproducts from the uranium ore have been successful. The results are summarized here.

\subsection{Recovery of uranium from copper tailings}

The tailings from the copper flotation plants, operated by $\mathrm{M} / \mathrm{s}$ Hindustan Copper Limited (HCL) at Surda, Rakha and Mosabani in the Singbhum district of Bihar contain uranium in low concentration $(80-100 \mathrm{ppm})$, which constitutes a readily available source. Investigations have led to gravity methods for upgrading the uranium values. These were followed by pilot plant tests and finally by full scale plants to treat 1000 tpd of tailings at Surda and Rakha.

The laboratory work for process development covered testing on Deister table, Holman table, Buckman tilting concentrator, Humphry's spirals, classification in a centrifugal classifier, multispigot classifier, cyclone and manual desliming. Several types of flow sheets including those with retreatment of midlings were studied. The final process made use of Wilfley tables operating in parallel. The concentrate from all the tables was combined and pumped to settling pits for dewatering. This is transported to the nearby uranium mill for chemical processing to obtain an 'yellow cake'.

The feed to the tables at Surda and Rakha analyses $100-120$ ppm of $\mathrm{U}_{3} \mathrm{O}_{8}$ while the one at Mosabani does $90-100 \mathrm{ppm}$. The table concentrate at the first two plants analyses $900-1000 \mathrm{ppm}$ and is $3 \cdot 7-4.5 \%$ by weight of the feed. At the Mosabani pilot plant the concentrate is $650 \mathrm{ppm} \mathrm{U}_{3} \mathrm{O}_{8}$ which is about $3 \%$ by weight of the feed. 
While the overall uranium recovery in the concentrate is $35-40 \%$ in the first two plants it is only $21 \%$ in the Mosabani pilot plant.

With a view to improving the recovery various factors were investigated. It was found that an appreciable fraction of uranium is distributed in the fraction finer than $37 \mu$ and recovery from these fines is low on Willey tables. A modified flow sheet involving wet screening of feed slurry, concentration of coarse material on Wilfley tables and concentration of fines on a slime concentrator like Bartles-Mozby separator (BMS) for rougher operation has been worked out. The overall recovery is expected to be $60 \%$.

\subsection{Recovery of sulphide minerals from Jaduguda uranium ore}

The uranium ore from Jaduguda mine, handled by the Uranium Corporation of India Limited, contains small amounts of sulphide minerals of $\mathrm{Mo}, \mathrm{Cu}$ and $\mathrm{Ni}$ (Mo $0.01 \%, \mathrm{Cu} 0.1 \%, \mathrm{Ni} 0 \cdot 12 \%$ ). In view of the lack of molybdenum resources and the absence of production of nickel in the country an $R$ and $D$ programme was launched at BARC to recover the three metal sulphides as byproducts though they were present in low concentration. These efforts have led to the establishment of the Byproduct Recovery Plant (BRP) at Jaduguda. The sulphide minerals are recovered from the ground ore before it goes to uranium recovery by sulphuric acid leaching. The process (figure 1) includes conditioning of ore slurry in alkaline medium with Creosotes, prior to rougher floatation. The bulk sulphide float, thus obtained, is cleaned and the nickel minerals are separated in two stages by sodium silicate conditioning. Differential flotation of molybdenite is then carried out using sodium sulphide in three stages. After cleaning a molybdenite concentrate with $+45 \% \mathrm{Mo}$ is obtained for marketing. The copper concentrate is accepted by the Hindustan Copper Limited for smelting. The plant has been satisfactorily operating for over a

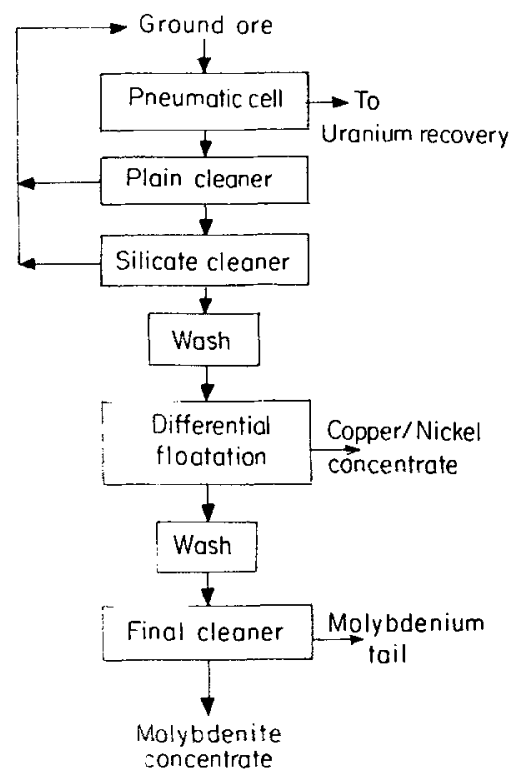

Figure 2. Howsheet for Jaduguda byproduct recovery plant. 
decade and now accounts for a small but the only indigeneous, production of molybdenite.

To complete the utilization of the copper and nickel minerals produced in BRP a hydrometallurgical process based on salt roasting, water leaching and solvent extraction process has been worked out on a laboratory scale and later on a pilot plant scale. The final products are high grade copper and nickel sulphates.

Another important byproduct from the uranium ore is magnetite recovered from leach residues of the uranium mill by drum magnetic separators.

The recovery of uranium as byproduct from copper tailings and in turn, recovery of copper, nickel and molybdenum from the uranium ore represent successful implementation of mineral conservation measures in a country, not richly endowed with mineral wealth.

\section{Beach sand minerals}

In many countries the silt carried by the rivers to the sea contains some minerals of economic value. The chemically and mechanically stable minerals are, under favourable conditions, beneficiated by natural processes and get concentrated along the beaches and sand dunes. In India also, mineral-rich beach sands (table 1) have been exploited for over half a century. M/s Indian Rare Earths (IRE), a major organization under the administrative control of DAE runs many sand beneficiation and downstream chemical industries. Till recently the monazite rich sands of Manavalakurichi (Tamil Nadu) and ilmenite-rich sands of Chavara (Kerala) were the two major deposits used by IRE for production of ilmenite, rutile, zircon, monazite, sillimenite and garnet. During the last few years the sand dunes in Chatrapur in Orissa have been taken up for exploitation.

The Manavalakurichi (MK) and Chavara beach washings contain more than $80 \%$ heavies which, after mining, are transported and fed to the 'dry plant'. For exploiting the somewhat lower grade dune deposits a preconcentration is required. Spirals are used for this purpose. The individual minerals are separated in the 'dry mill' based on the physical properties of the individual minerals and a combination of several methods. Quartz, shells, sillimenite and garnet are of coarser grain compared to ilmenite, rutile, monazite and zircon.

According to the specific gravity monazite, zircon, ilmenite and rutile are considered heavy (sp. gr. 5.3-4.2), garnet and sillimenite are medium heavy (sp. gr. 3.1-4.3) and quartz is light (sp. gr. 2.65). Ilmenite, garnet and monazite are in

Table 1. Heavy resources in India and other countries.

\begin{tabular}{lccl}
\hline Mineral & \multicolumn{2}{c}{ Resources $\left(10^{6}\right.$ tonns $)$} & \\
\cline { 2 - 3 } Ilmenite & India & Other countries & \\
$\begin{array}{l}\text { Rutile } \\
\text { Monazite }\end{array}$ & 146 & 1722 & $\begin{array}{l}\text { Canada, Norway, S. Africa, USA, Aus- } \\
\text { tralia, Malaysia, Sri Lanka } \\
\text { Australia, Brazil, Sierra Leone, USA } \\
\text { Australia, Brazil, Egypt, USA, USSR, Sri } \\
\text { Lanka, Thailand, Malaysia } \\
\text { Australia, S. Africa, USA, USSR and } \\
\text { others }\end{array}$ \\
\hline
\end{tabular}


decreasing order of magnetic susceptibility. Ilmenite and rutile are conducting and the other minerals are non-conducting of electric charge. Sillimenite can be preferentially floated from a mixture of zircon, sillimenite and quartz. The difference in properties of the different minerals is reflected in the simplified flow sheet for their separation at OSCOM (figure 3 ).

\subsection{Present status of beach sand industry}

The present capacity of the MK plant is 400 tpd of preconcentrated feed, that of the Chavara plant 650 tpd of beach washings and that of the mill at Chatrapur 1000 tpd of preconcentrate feed. The IRE plants have an annual production capacity of $200,000 \mathrm{t}$ of ilmenite, 9,000 $\mathrm{t}$ of rutile, 13,000 $\mathrm{t}$ of zircon and 4,000 $\mathrm{t}$ of monazite. The annual production from Orissa operation will be $220,000 \mathrm{t}$ of ilmenite, $10,000 \mathrm{t}$ of rutile, $2,000 \mathrm{t}$ of zircon and 4,000 $\mathrm{t}$ of monazite.

The Kerala Minerals and Metals Limited (KMML) also operates a small dry mill to cater to the raw material needs of their synthétic rutile and pigment plants.

In addition, a series of downstream industries have been set up for further economic utilization of the minerals. They include the monazite processing plant for producing thorium and a variety of rare earth products, the synthetic rutile plant at Chatrapur, the titanium pigment plant near Quilon and another synthetic rutile and pigment plant by KMML.

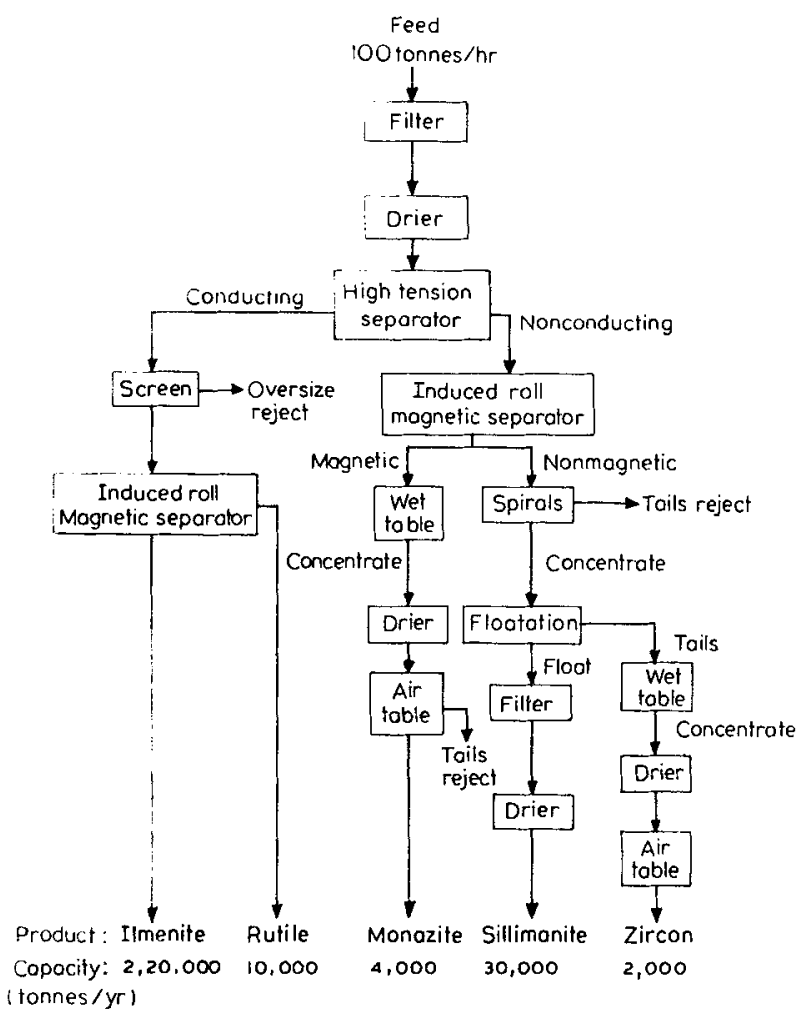

Figure 3. Mineral separation plant. 


\subsection{Utilization of minerals}

Of the important minerals produced by beach sand beneficiation, ilmenite, rutile and zircon are partly used in the country and partly exported; monazite is chemically processed in the rare earth plant of IRE.

One of the typical processing facilities is that for zircon. The Nuclear Fuel Complex (NFC) of DAE processes this mineral to obtain zircaloy cladding for uranium oxide ceramic fuel for nuclear power reactors. The important steps involved in this chain of processes are

(i) zircon is reacted by heating with $\mathrm{NaOH}$ and the sodium silicate formed is washed off;

(ii) the resultant crude zirconium hydrous oxide is dissolved in nitric acid and by liquid-liquid extraction zirconium is separated from hafnium and other impurities;

(iii) from the organic phase zirconium is stripped with water and finally recovered as oxide;

(iv) the oxide is converted into chloride and by metallothermic reduction zirconium sponge is obtained using magnesium;

(v) the sponge is arc-melted and converted into a billet, which by a series of mechanical processing steps is transformed into various types of tubes and components required for fuel cladding and reactor use.

It is perhaps a unique situation in this country that all the stages of processing starting from concentration of the minerals from beach sands to fabrication of nuclear components are achieved in DAE, with technology developed and adopted internally.

\section{Processing of other minerals}

When DAE was looking for tantalum ores to produce the metal powder for capacitors and the niobium ores for the metal to be used for alloying zirconium (for nuclear fuel cladding) it was found that the country did not have an assured supply of mineral resources for these two metals. However, the Atomic Minerals Division of DAE was able to identify low grade ores for which a beneficiation process has been worked out.

\subsection{Niobium}

The fluoride-bearing granites of Kanigiri (Andhra Pradesh) carry traces of heavy minerals, including columbite. The top soil cover up to $50 \mathrm{~cm}$ depth is enriched in the minerals consisting of ilmenite, magnetite, columbite, rutile, garnet, zircon, allanite samerskite and fluorite. The average $\mathrm{Nb}_{2} \mathrm{O}_{5}$ content is $75 \mathrm{ppm}$.

Size analysis of the soil samples showed that over $50 \%$ of the gangue is in sizes coarser than $420 \mu$ while practically all the heavy minerals are in the finer fraction. Therefore, by a single classification $50 \%$ of the gangue can be separated. Gravity separation has been adopted to remove most of the quartz and feldspar. A further cleaning yields a preconcentrate forming about $0 \cdot 14 \%$ by weight of the raw soil and analysing about $3.5 \% \quad \mathrm{Nb}_{2} \mathrm{O}_{5}$. Electrostatic separation (magnetite, ilmenite, 
columbite and rutile being conducting) followed by a magnetic separation of this fraction (out of the conducting minerals columbite is weakly magnetic, while magnetite and ilmenite are strongly magnetic and rutile is non-magnetic) results in the columbite concentrate analysing $44-45 \% \quad \mathrm{Nb}_{2} \mathrm{O}_{5}$ with $60 \%$ recovery.

The chemical process for production of pure $\mathrm{Nb}_{2} \mathrm{O}_{5}$ consists of attack of the concentrate with hydrofluoric acid-sulphuric acid mixture and solvent extraction separation of tantalum followed by niobium. Niobium oxide, recovered by precipitation and calcination is reduced with calcium to obtain niobium.

\subsection{Beryllium}

The beryllium mineral of commercial interest is beryl $\left(3 \mathrm{BeO} \cdot \mathrm{Al}_{2} \mathrm{O}_{3} 6 \mathrm{SiO}_{2}\right)$. One of the main applications of beryllium is in the manufacture of $\mathrm{Cu}-2 \% \mathrm{Be}$ alloy. In the nuclear field Be finds limited application as neutron reflector and moderator in some experimental reactors. The US Bureau of Mines estimated the world beryllium resources as Brazil 154,000 t, India 71,000 $\mathrm{t}$ and USSR 67,000 $\mathrm{t}$. In the case of China the beryllium resources are not known but are likely to be appreciable.

Much of the beryl in India is obtained from pegrnatites in Bihar, Rajasthan, Andhra Pradesh, Karnataka, Madhya Pradesh and Orissa. The entire activity relating to beryl production, acquisition, use and disposal is being controlled by DAE.

Toxicity of beryllium has been a major deterrant for the development of new applications and technology. Toxicity is mainly due to inhalation causing either acute or chronic lung diseases. The permissible inplant limit of $2 \mu \mathrm{g}$ of Be per cubic meter of plant air was recommended by the USAEC.

A small plant for the production of Cu-Be alloy and beryllium powder has been established by BARC. It has a capacity to produce $250 \mathrm{~kg}$ of high purity Be metal and $10 \mathrm{t}$ of $\mathrm{Cu}-2 \% \mathrm{Be}$ alloy annually.

Briquettes of a mixture of ground beryl, sodiumsilicofluoride, iron crylite and sodium carbonate are heated at $700-750^{\circ} \mathrm{C}$ to decompose the ore. The water-solubie sodium beryllium fluoride is leached out with water. From the solution iron is precipitated by raising the $\mathrm{pH}$ to around $7 \cdot 2$ and then beryllium itself is precipitated by raising the $\mathrm{pH}$ to $11-13$. The hydroxide is converted to $\mathrm{BeNH}_{4} \mathrm{~F}_{2}$ and by heating at $125^{\circ} \mathrm{C} \mathrm{BeF}$ can be obtained. $\mathrm{By}$ reduction of $\mathrm{BeF}_{2}$ with magnesium metallic $\mathrm{Be}$ is produced. The beryllium pilot plant has been operating satisfactorily for the past 3 vears.

\section{Conclusion}

A number of special materials required for the nuclear and related programmes are produced in the country with technologies developed indigeneously and backed by research and development efforts. In many cases the operations undertaken by the Department of Atomic Energy start with mining of the raw material, and end with the final product which can be used in the reactor.

In the case of uranium the technology is mainly that of exploiting a low-grade ore. The recovery of uranium from copper concentrator tailings and the recovery of copper, nickel and molybdenum as byproducts from the uranium ore are examples of optimum utilization of scarce resources. 


\section{References}

Karve V M and Majumdar K K 1972 Silver Jubilee Symposium of the Indian Institute of Metals Robert C Meritt 1971 The extraction metallurgy of uranium Colorado School of Mines Research Singh H, Natarajan R, Das K K, Jha R S, Sridhar U, Rao N K and Rao C V U 1983 Atomic Energy Dept. Rep. No. BARC/I-771

Shukla P P, Mukherjee T K, Gupta C K, Nagle R N, Koppiker K S and Murthy T K S 1979 Trans. Inst. Min. Metall. C88 134

Viswamohan V, Shivananda S R, Dwivedi K K and Jayaram K M V 1981 Proc. Symp. on Advances in Science and Technol. of Mineral Beneficiation in India 